\title{
Desinformación de género: análisis de los bulos de Maldito Feminismo
}

\section{Gender disinformation: analysing hoaxes on Maldito Feminismo}

\section{Desinformação de gênero: análise das notícias falsas é a plataforma Maldito Feminismo}

\author{
Dra. Paula Herrero-Diz \\ Profesora, investigadora del departamento de Comunicación y Educación \\ (Universidad Loyola Andalucía) \\ http://orcid.org/0000-0002-8708-1004 \\ España \\ Dra. Marta Pérez-Escolar \\ Profesora asistente, Dpto. de Comunicación y Educación \\ (Universidad Loyola Andalucía) \\ https://orcid.org/0000-0003-2575-7993 \\ España \\ Dr. Juan F. Plaza Sánchez \\ Profesor titular, Dpto. de Comunicación y Educación \\ (Universidad Loyola Andalucía) \\ https://orcid.org/0000-0002-7741-088X \\ España
}

Fecha de recepción: 30 de noviembre de 2019

Fecha de revisión: 1 de febrero de 2020

Fecha de aceptación: 5 de marzo de 2020

Fecha de publicación: 1 de julio de 2020

Para citar este artículo: Herrero-Diz, P., Pérez-Escolar, M. y Plaza Sánchez, J.F. (2020). Desinformación de género: análisis de los bulos de Maldito Feminismo, Icono 14, 18 (2), 188-216. doi: 10.7195/ri14.v18i2.1509 


\section{Resumen}

El desorden informativo (sátira o parodia, conexión falsa, contenido engañoso, contexto falso, contenido impostor, contenido manipulado o contenido fabricado) es un problema social que empieza a demostrar sus daños colectivos. De forma particular, las mujeres están siendo víctimas de hostilidades en el escenario digital, lo que se conoce como "sexismo digital" y "desinformación de género". En este contexto, el periodismo de verificación, un formato tendencia y aún minoritario, trata de paliar los efectos de los bulos introduciendo, entre sus rutinas profesionales, el desmentido de esos contenidos. Para contribuir al estudio del fenómeno de la desinformación, en relación con los mensajes que circulan en Internet sobre las mujeres, esta investigación propone una herramienta de clasificación sistemática de los bulos desmentidos por el medio Maldita.es en su sección Maldito Feminismo ( $N=71)$. Esta herramienta, inspirada en las taxonomías de Derakhshan \& Wardle (2017), Tandoc, Lim \& Ling (2018) y Molina, Sundar, Le \& Lee (2019), permite clasificar las noticias falsas según el tipo de desorden informativo, el agente, el mensaje y el intérprete.

Los resultados de este estudio (que tienen una validez interna) revelan que los bulos detectados por Maldito Feminismo son noticias falsas de contenido engañoso, que buscan dañar el feminismo (ya que este es el tema principal de la mayoría de bulos analizados) y tienen un propósito político. Estos desórdenes informativos se crean y distribuyen, principalmente, a través de las redes sociales en formato texto. Normalmente, es la propia plataforma-Maldito Feminismo- quien identifica, localiza y delata la mayoría de noticias falsas.

Palabras clave: Feminismo; Verificación; Bulo; Desinformación; Género; Noticias falsas

\section{Abstract}

Information disorder (satire or parody, false connections, misleading content, false context, imposter content, manipulated content or fabricated content) is a social problem that is causing collective damages. Women, in particular, are becoming victims of hostilities on the digital scenario. This problem is currently known as "digital sexism" and "gender disinformation". In this context, verification journalism, a trendy format, aims to reduce the effects of hoaxes introducing the fact-checking 
process in its professional routines. However, this is still a minority task. In order to contribute to the study of the disinformation phenomenon in relation to online messages about women, this research has developed a systematic tool to classify hoaxes that have been refuted by the platform Maldita.es, specifically, on its sections Maldito Feminismo $(N=71)$. This tool, inspired by the taxonomies created by Derakhshan \& Wardle (2017), Tandoc, Lim \& Ling (2018) and Molina, Sundar, Le \& Lee (2019), allows you to categorize fake news according to the type of information disorder, the agent, the message and the interpreter.

The results of this study (internal validity) show that hoaxes detected by Maldito Feminismo are misleading content that expect to damage feminism (this is the main topic of fake news) and have a political purpose. These information disorders are displayed in text format and are mainly created and distributed on social networks. Moreover, although users collaborate and participate detecting and reporting hoaxes, the platform Maldito Feminismo identifies, locates and denounces most of the fake news.

Key Words: Feminis; Fact-checkin; Hoax; Disinformation; Gender; Fake news

\section{Resumo}

A desordem informativa (sátira ou paródia, conexão falsa, conteúdo enganoso, contexto falso, conteúdo impostor, conteúdo manipulado ou conteúdo fabricado) deve ser considerada um problema social enquanto os danos coletivos que provoca e que ameaçam à sociedade digital começam a ser descobertos. Particularmente, as mulheres são vítimas de hostilidades nos espaços de interação virtuais. Esse fenômeno é conhecido como "sexismo digital" e "desinformação de gênero".

Neste cenário, o jornalismo de verificação (oufact checking journalism em inglês), um formato que é tendência, tenta paliar os efeitos das calúnias ou difamações a introduzir nas rotinas profissionais a prática de desmascarar essas calúnias. Contudo ainda é um trabalho pouco expandido. Para contribuir ao estudo do fenômeno da desinformação em relação com as mensagens que circulam na Internet sobre as mulheres, esta investigação propõe uma ferramenta de classificação sistemática das calúnias desmascaradas pela Maldita.es na seção Maldito Feminismo ( $N=71$ ).

Os resultados deste estudo revelam que as calúnias detectadas pela seção Mal- 


\section{MONOGRÁFICO}

dito Feminismo são notícias falsas de conteúdo enganoso. Esses conteúdos têm a intenção de prejudicar ao feminismo (este é o assunto principal da maior parte das calúnias analisadas) com um propósito político. Essas desordens informativas são criadas e distribuídas principalmente pelas redes sociais na forma de texto. Embora os usuários colaboram e participam na detecção e denúncia dessas calúnias, é a plataforma Maldito Feminismo à que frequentemente identifica, localiza e desmascara a maior parte das notícias falsas.

Palavras chave: Feminismo; Verificação; Calúnias; Desinformação; Gênero; Notícias falsas

\section{Introducción}

El fenómeno de la desinformación, definida por la Comisión Europea (2018) como aquella "información falsa, inexacta o engañosa diseñada, presentada y promovida para causar daño público intencionalmente o con fines de lucro" (p.10), genera 213 millones de euros anuales en ingresos publicitarios a través de las 20.000 páginas web identificadas como espacios de riesgo (Global Disinformation Index, GDI, 2019). Además, la mentira pone en peligro los procesos y valores políticos democráticos, como denuncia la CE: "ocho de cada diez ciudadanos consideran que se trata de un problema general para la democracia" (Eurobarómetro, 2018, p.4). La desinformación también está afectando a sectores como la salud, la ciencia, la educación o la economía, superponiendo las emociones por encima de los hechos y evidencias. En este contexto, los ciudadanos comienzan a mostrar su inquietud sobre los bulos: un $79 \%$ de los españoles afirma que, a menudo, encuentra distintos tipos de engaño en la red $\mathrm{y}$, lo que es más preocupante, solo la mitad cree poder diferenciar estos contenidos de la verdad. Por tanto, parece lógico, como reivindican Pal \& Banerjee (2019), que se investigue a fondo la desinformación y considerar este fenómeno como un problema social (social problem), ya que implica daños colectivos que amenazan a la sociedad digital.

Entre los peligros más acusados que supone la propagación de información incorrecta y aquella que tiene la intención deliberada de engañar, se esconden las motivaciones ideológicas $\mathrm{y}$, en concreto, cobra fuerza el ataque a cuestiones rela- 
cionadas con las mujeres (Lewis \& Marwick, 2017). En los inicios de la tercera ola feminista (años 60), la activista Gloria Steinem (2016) explica, en sus memorias, cómo las mujeres ya tuvieron que desmentir las manipulaciones de los medios: “A saber, que éramos todas "blancas de clase media»" (p. 93). 0cceñola (2018) describe ese tipo de ataques directos contra su identidad como mujeres como "desinformación de género". Sobieraj (2018) lo llama "sexismo digital" (p.1702) y explica que las mujeres se enfrentan, en Internet, a un abuso digital basado en el género; una hostilidad extrema, en los espacios de interacción, donde se pueden verter comentarios de todo tipo. Occeñola (2018) señala el caso de Filipinas, donde la organización no gubernamental Foundation for Media Alternatives (FMA) denunció el acoso a mujeres periodistas y políticas, tras las elecciones de 2016, a través de las declaraciones de Jamela Alindogan, corresponsal de Al-Jazeera en Manila: «Creo que las mujeres son vulnerables a todo tipo de rumores, pero a menudo son vilipendiadas por sus apariencias físicas y sus vidas personales». Así como las de la vicepresidenta del Gobierno de Filipinas, Leonor Robredo: «Las mujeres en la política son objetivos constantes de acoso sexual, ataques morales y críticas contra sus familias. La mayoría de las cosas que se han dicho sobre mí son ataques contra mí como mujer».

Por su parte, Pardy (2018) también recoge otros ejemplos de mujeres (en este caso, de activistas musulmanas) de reconocido prestigio, en la sociedad, que han sido difamadas en los medios, víctimas de montajes, manipulaciones y toda clase de tergiversaciones de su imagen o palabras. En su artículo para Refinery29, Pardy (2018) afirma que "la misoginia es tanto la entrada como la salida que mantiene a flote la industria de las noticias falsas". El estudio de la compañía holandesa de ciberseguridad Deeptrace confirma que, dentro de esta industria, que mueve millones de dólares, existe un formato en tendencia: los vídeos manipulados, mediante inteligencia artificial, que suplantan el rostro de una persona y cuyas principales víctimas son las mujeres. Son los llamados deepfakes y su uso es, además, fundamentalmente pornográfico (Ajder, Patrini, Cavalli \& Cullen, 2019).

En el caso de España, el Consejo Audiovisual de Cataluña (CAC) publicó, en 2018, un primer informe sobre las fake news en Internet y el discurso de género, en 
el que evidencia, a través del análisis de 12 tipos de informaciones, que las mujeres están sufriendo la construcción de un relato, en Internet, que perjudica su imagen: contenidos falsos fabricados ad hoc, manipulación y distribución de contenidos de corte satírico. Sin embargo, este informe también revela que los desmentidos sobre informaciones falsas que circulan sobre las mujeres, por su condición de mujer, son minoritarios. Entre las ideas que contienen estas informaciones engañosas, abunda la consideración de las mujeres como inferiores a los hombres y el cuestionamiento de las políticas de género. Por otro lado, el estudio también advierte de que estos mensajes están teniendo eco entre la opinión pública que los comparte y que, a largo plazo, esto puede favorecer la creación de "guetos digitales" o "ciberguetos" (Johnson, Bichard \& Zhang, 2009, p.60).

Para ello, el CAC propone la educación como forma de hacer frente a este fenómeno. En el curso 2017/2018, se puso en marcha, dentro del Programa eduCAC, una guía para ayudar al profesorado, a los estudiantes y a sus familias a detectar noticias falsas. Con la intención de contribuir al estudio de la desinformación, como un problema social, como defienden Pal \& Banerjee (2019), que afecta, en este caso, a las mujeres y de reivindicar la labor que cada vez ejercen más medios dedicados a la verificación de contenidos falsos o engañosos, esta investigación tiene como objetivo estudiar el desorden informativo (Derakhshan \& Wardle, 2017) en relación con los mensajes que circulan en Internet sobre las mujeres como colectivo.

Por ello, el objetivo de este estudio es analizar los bulos desmentidos por el medio Maldita.es, en concreto, aquellos publicados en su sección Maldito Feminismo. De esta forma, se quiere dar respuesta a las siguientes preguntas de investigación:

- PI_1: ¿Qué tipo de desorden informativo afecta a los mensajes sobre las mujeres en Internet?

- PI_2: ¿Quiénes son los agentes implicados en el desorden informativo sobre los mensajes que circulan sobre las mujeres en Internet?

- PI_3: ¿Qué características presentan los bulos sobre las mujeres publicados en Internet? 


\subsection{La verificación como formato}

La verificación (del inglés fact-checking) responde al proceso sistemático de comprobación de datos y hechos (Echevarría, 2016). Algunos estudios ya demuestran que, aunque este formato no es un género para todos los públicos, sí que contribuye a que los usuarios estén mejor informados (Nyhan \& Reifler, 2015). En los últimos años, son numerosas las iniciativas periodísticas nacidas para verificar el discurso político, en un intento de "aumentar el bienestar de la comunidad en la que se integran, así como aumentar la transparencia de sus administraciones" (Magallón, 2018, p.280). El último informe sobre este tipo de medios de verificación cifra en 210 las plataformas dedicadas a esta tarea: Maldita.es, Chequeado, Bolivia Verifica, Reverso, Verificado Uruguay, Namibia FactCheck, GhanaFact, Verify-Sy, Metafact, India Today Fact Check, etc. (Stencel \& Luther, 2019). Mientras que, en la mayoría de los medios tradicionales, se han creado unidades específicas de comprobación de la información, como en el caso de la agencia EFE, Televisión Española, Le Monde o la BBC, entre otros. Sin embargo, no todas estas plataformas hacen lo mismo, ni de igual manera, ya que existen diferentes metodologías de verificación, formas de presentar cómo se han contrastado los hechos, narrativas y modelos de negocio (sin fines de lucro o buscando la rentabilidad), pero todas coinciden en algo y es en el surgimiento de un nuevo tipo de periodismo: el de verificación.

Con todo, los orígenes de la verificación no se encuentran en Internet, sino en los analógicos años 20, en revistas estadounidenses como Time, donde sus responsables eran, fundamentalmente, mujeres. Así lo recoge la periodista Merril Fabry (2017) en su reportaje, donde describe el escrupuloso proceso de comprobación de la información que utilizaban sus colegas periodistas antes de publicar una noticia: basándose en un sistema de puntos y colores, colocaban un punto sobre cada palabra una vez que hubiera confirmado su precisión (rojas para hechos verificados de fuentes autorizadas, como libros de referencia; negros cuando un hecho se obtuvo de un periódico; y puntos verdes para palabras o frases no verificables que un corrector aceptó bajo la autoridad del autor). Lo más curioso de aquella labor eran las fuentes y materiales de verificación a los que recurrían: la Biblioteca Pública de Nueva York, una copia de The World Almanac, algunos de 
los libros de Hadden, un diccionario, un tesauro, una Biblia y recortes de periódicos. Aquella actividad no tiene nada que ver con la de hoy: en la actualidad, la verificación de hechos se ha convertido en un género propio, que consiste en elaborar informaciones sobre los errores que otra persona ha cometido; mientras que, en sus inicios, era una actividad propia del proceso editorial para evitar errores de publicación. Fabry (2017) recoge una reflexión de Lucas Graves, investigador principal del Reuters Institute, sobre el periodismo actual: "lo que es diferente es la misión". En este sentido, Echevarría (2016) se pregunta si corresponde a los medios vigilar cada frase de los representantes públicos o si deben destinar parte de su actividad a comprobar los bulos en la red y explicarlos en ese mismo escenario.

El trabajo de Graves (2017) apoya la verificación en los medios, pues se trata de una actividad prestigiosa que defiende los ideales de la profesión periodística (Graves, Nyhan, \& Reifler, 2016), pero hay que objetivar esta tarea para no responder a fines partidistas o ideológicos acordes con las líneas editoriales de los medios o sus intereses económicos. En un trabajo anterior, Graves (2013) sostiene, por ejemplo, que Media Matters, un medio orientado a la izquierda, monitorea y combate las afirmaciones hechas por expertos y políticos republicanos, mientras que NewsBusters, que pertenece a un grupo conservador, vigila las declaraciones de dirigentes liberales. En cualquier caso, Graves (2013) señala cinco tareas clave que los periodistas tienen que desempeñar para comprobar los hechos: encontrar declaraciones para verificar (choosing claims to check); contactar con el autor de esas declaraciones (contacting the speaker); rastrear declaraciones falsas (tracing false claims); tratar con expertos y mostrar su trabajo (working with experts).

Por otro lado, existe una manera complementaria de ejercer la verificación: utilizar una aplicación de software de inteligencia artificial, que tiene como objetivo emplear la tecnología para identificar el contenido intencionalmente engañoso de noticias en línea (Conroy, Rubin, \& Chen, 2015). Estos programas permiten detectar características propias del engaño: titulares llamativos, expresiones de tono humorístico, ausencia de fuentes, páginas web fraudulentas, trols, lenguaje soez, errores ortográficos o imágenes trucadas. Además, dada la cantidad ingente y la 
velocidad de los contenidos engañosos que se publican y distribuyen en Internet, estas herramientas automatizadas facilitan las rutinas de los periodistas (Brandtzaeg et al., 2016; Hermida, 2015).

\subsection{Feminismo y activismo de verificación}

Desde sus orígenes, el feminismo se ha considerado un movimiento "impertinente" (Valera, 2013), es decir, que incomoda e irrita. Por ello, como describe Valera (2013), es habitual que, al pronunciar la palabra feminismo, "nuestros interlocutores tuercen el gesto, muestran desagrado, se ponen a la defensiva 0 , directamente, comienza la refriega" (p.13). Como cualquier manifestación activista, el feminismo es un ejemplo de desobediencia civil (Bedau, 1961; Habermas, 2002; Magaloni, 1990; Marcone, 2009; Rawls, 1979; Thoureau, 2002) porque surge en un contexto de frustración social, con el fin de reivindicar el valor de las mujeres como "seres humanos libres, dueñas de su destino, aptas para ganarse la vida y para gozarla sin que su condición se lo impida" (Mastretta, p.54).

El concepto de desobediencia civil suele malinterpretarse y tiende a percibirse como un fenómeno social que intenta desestabilizar el sistema democrático. Sin embargo, la desobediencia civil no es una manifestación ácrata, sino un método de oposición no violenta que utilizan los ciudadanos para expresar su desaprobación por las injusticias sociales. Por tanto, el feminismo, como movimiento de desobediencia civil, no solo es un mecanismo de participación ciudadana, sino también una expresión legítima de poder ciudadano; es decir, que cualquier Estado democrático debe respaldar el derecho de las mujeres y hombres a poder manifestarse contra cualquier iniquidad (Habermas, 2002).

Sin embargo, a pesar de lo expuesto, el feminismo es, en la actualidad, una lid social entre los antagonistas de esta forma de protesta, porque lo conciben como un movimiento antihombres, y los simpatizantes, que entienden el feminismo como una lucha necesaria para lograr que mujeres y hombres tengan los mismos derechos (Carreón \& Garza, 2016). 
Esta demonización o negación del feminismo no es un fenómeno nuevo (De Miguel, 2008). Diversos autores (Gill, 2007; McRobbie, 2007; Lazar, 2009; Hammer \& Kelner, 2009; Press, 2011; Stabile, Grant, Purohit \& Harris, 2019; Wichels, 2019) han denunciado esta situación que ha marcado el activismo feminista desde sus albores. La principal diferencia es que, hoy en día, el poder de divulgación de las tecnologías de la comunicación no solo ha ampliado el eco de las voces que vituperan el feminismo, sino que, además, ha favorecido que la desinformación sea el principal aliado de los ciberguetos antifeministas. Tal y como denunciaban Pal \& Banerjee (2019), los bulos se han convertido en un problema social significativo en el escenario digital, pues la culpa de la demonización del feminismo la tiene, en parte, la desinformación. Para Marwick y Lewis (2017), los principales responsables de manipular la información sobre temas feministas son el movimiento alt-right: una amalgama que congrega a supremacistas blancos, nacionalistas blancos, troles, antifeministas, defensores de los derechos de los hombres, activistas antiinmigración, jóvenes aburridos, etc.

Ante esta situación, han surgido, en la red, un mosaico de contramovimientos activistas que buscan identificar y destapar los bulos e informaciones engañosas relacionadas con el feminismo o con cualquier otro tema social o político. Este tipo de activismo de verificación busca alfabetizar a la sociedad, promover una conciencia colectiva y mantener activo el espíritu de crítica. En cierto sentido, el activismo de verificación es similar al activismo mediático (Rovira, 2013; Barranquero \& Meda, 2015; Domínguez, 2015), pues ambos se conforman como una fuerza alternativa a los medios tradicionales. Sin embargo, la principal diferencia que caracteriza al activismo de verificación es que este se enfoca, única y exclusivamente, en contrastar los mensajes dudosos y combatir la desinformación, aunque conserva muchos hábitos propios de las rutinas periodísticas. No obstante, el activismo de verificación vigila las publicaciones de los medios tradicionales y los discursos políticos con el fin de detectar las noticias falsas e informar sobre la veracidad de los hechos.

Desde la perspectiva del feminismo, la labor de este activismo de verificación se enmarca, además, como una de las actividades propias de lo que, hoy en día, se conoce como la cuarta ola del feminismo o ciberfeminismo (Fernández, Corredor 
\& Santín, 2011; García Aguilar, 2015; Núñez Puente, 2016; Moghaddam, 2019; McAdam, 2020). En este sentido, este nuevo movimiento ciberfeminista no solo implica una revolución sexual de la mujer (Plant, 1998), sino que también conlleva trasladar las luchas por la igualdad de género y el empoderamiento de la mujer al ecosistema digital.

En el contexto español, una de las principales plataformas de activismo de verificación es Maldita.es. Estudios como los de Coromina \& Padilla (2018), donde se analizan las desinformaciones contrastadas por Maldito Dato (concretamente, aquellas que han sido desmentidas a través de su cuenta de Twitter) relacionadas con los acontecimientos del 1 de octubre de 2017 en Cataluña, o los de Molina \& Magallón (2019), centrado en examinar los tuits de Maldita Migración (@m_migracion), refuerzan la importancia de continuar investigando sobre las consecuencias de la desinformación en la sociedad actual. Por ello, en este trabajo, hemos considerado conveniente analizar los bulos detectados por Maldito Feminismo, en su página web, con la intención conocer, desde una perspectiva holística, las principales características e intenciones de las noticias falsas relacionadas con el feminismo.

\section{Material y métodos}

El objetivo principal de este estudio es analizar los bulos desmentidos por Maldita.es en su sección Maldito Feminismo. En concreto, esta investigación busca dar respuesta a las siguientes preguntas de investigación:

- PI_1: ¿Qué tipo de desorden informativo afecta a los mensajes sobre las mujeres en Internet?

- PI_2: ¿Quiénes son los agentes implicados en el desorden informativo sobre los mensajes que circulan sobre las mujeres en Internet?

- PI_3: ¿Qué características presentan los bulos sobre las mujeres publicados en Internet? 
MONOGRÁFICO

Para ello, en este estudio, de corte cuantitativo y cualitativo, se propone una herramienta para el análisis sistematizado de contenido, con fines "clasificatorios y de resumen" (Fox, 1981, p.709), de todos los bulos desmentidos por el medio de verificación Maldito Feminismo ( $\mathrm{N}=71$ ). El diseño de este método permite realizar inferencias sobre los contenidos (Bardín, 1991). Este procedimiento se llevó a cabo en tres fases, como propone el autor:

- $1^{\text {a }}$ Preanálisis: se formulan los objetivos de la investigación y las hipótesis; se seleccionan los bulos (eliminando enlaces rotos y aquellos erróneamente etiquetados) y se diseña el instrumento para el análisis de contenido (elaboración del libro de codificación y de la ficha de clasificación).

- $2^{\text {a }}$ Explotación del material: se codifican los mensajes utilizando, para ello, las categorías y subcategorías definidas en la ficha de análisis o clasificación.

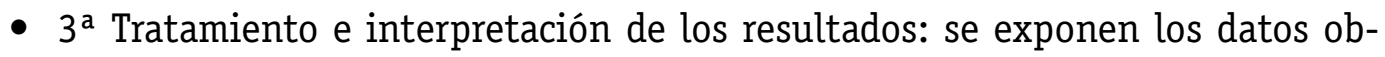
tenidos.

\subsection{Diseño de la herramienta}

Para llevar a cabo el análisis de los bulos, desarrollamos un instrumento inspirado en el método taxonómico: una ficha de clasificación (basada en la teoría de Derakhshan \& Wardle, 2017, Tandoc, Lim \& Ling, 2018 y Molina, Sundar, Le \& Lee, 2019) que contiene las unidades de análisis, las categorías y subcategorías en las que se puede catalogar un bulo (Tabla 1). Todo ello quedó recogido, a su vez, en un libro de codificación.

Para comprobar la fiabilidad de la herramienta, los codificadores procedieron a la clasificación de una serie de informaciones administrando la ficha de análisis. Sobre esta primera prueba, se aplicó el alpha de Krippendorff (2018), tras el que obtuvimos un $100 \%$ de fiabilidad. Como explica Bardin (1991, p.27), para que el análisis sea válido, dos codificadores diferentes deben llegar a los mismos resultados. En este caso, los tres expertos clasificaron igual las informaciones. 


\begin{tabular}{|c|c|c|c|c|c|c|}
\hline \multicolumn{7}{|c|}{ TICHA DE ANÁLISIS } \\
\hline \multicolumn{7}{|c|}{ Tipo de desorden informativo } \\
\hline $\begin{array}{c}\text { Sátira o } \\
\text { parodia }\end{array}$ & $\begin{array}{c}\text { Conexión } \\
\text { falsa }\end{array}$ & $\begin{array}{c}\text { Contenido } \\
\text { engañoso }\end{array}$ & $\begin{array}{c}\text { Contexto } \\
\text { falso }\end{array}$ & $\begin{array}{c}\text { Contenido } \\
\text { impostor }\end{array}$ & $\begin{array}{c}\text { Contenido } \\
\text { manipulado }\end{array}$ & $\begin{array}{c}\text { Contenido } \\
\text { fabricado }\end{array}$ \\
\hline \multicolumn{7}{|c|}{ Elementos del desorden informativo según el AGENTE } \\
\hline Televisión & Prensa & $\begin{array}{c}\text { Redes } \\
\text { sociales }\end{array}$ & $\begin{array}{c}\text { Radio } \\
\text { Elementos del desorden informativo según el MENSAJE }\end{array}$ & Anónimo & Particulares & Colectivos \\
\hline Tema & $\begin{array}{c}\text { Violencia } \\
\text { de género }\end{array}$ & Feminismos & $\begin{array}{c}\text { Personajes } \\
\text { de } \\
\text { actualidad }\end{array}$ & Curiosidades & $\begin{array}{c}\text { Mujeres en } \\
\text { la historia }\end{array}$ & Derechos y \\
legislación \\
\hline Formato
\end{tabular}

Tabla 1: Ficha de análisis de bulos.

Fuente: Elaboración propia inspirada en Derakhshan \& Wardle (2017),

Tandoc y Lim \& Ling (2018) y Molina, Sundar, Le \& Lee (2019).

\subsection{El libro de codificación (elementos)}

Las unidades, categorías y subcategorías, recogidas en la ficha de análisis, fueron definidas en el libro de codificación y están inspiradas en las taxonomías de Derakhshan \& Wardle (2017), Tandoc, Lim \& Ling (2018) y Molina, Sundar, Le \& Lee (2019), así como reconocidas y avaladas por la comunidad científica por su precisión y flexibilidad. Estos autores se refieren a las coloquialmente conocidas como "noticias falsas" como un desorden informativo con diferentes características formales e intenciones. 


\section{Tipo de desorden informativo}

- Sátira o parodia: información de carácter jocoso sobre un hecho real, que puede convertirse en información errónea cuando el público malinterpreta el mensaje. No pretende causar daño.

- Conexión falsa: cuando los titulares, imágenes o leyendas no confirman el contenido.

- Contenido engañoso: uso engañoso de la información para incriminar a alguien 0 algo.

- Contexto falso: cuando el contenido genuino se difunde con información de contexto falsa.

- Contenido impostor: cuando se suplantan fuentes genuinas.

- Contenido manipulado: cuando la información, el contenido o imágenes genuinas se manipulan para engañar.

- Contenido fabricado: contenido nuevo, que es predominantemente falso, diseñado para engañar y perjudicar.

Elementos del desorden informativo según el agente: quiénes fueron los agentes que crearon, produjeron y distribuyeron el bulo, con la intención de hacer daño.

- Televisión: el bulo ha sido creado, producido o distribuido por una televisión.

- Prensa: el bulo ha sido creado, producido o distribuido por un periódico 0 revista digital/impreso o agencia.

- Redes sociales: el bulo ha sido creado, producido o distribuido desde alguna cuenta en una red social.

- Radio: el bulo ha sido creado, producido o distribuido por algún medio radiofónico.

- Anónimo: el bulo no tiene un agente identificado.

- Particulares: el bulo ha sido creado, producido o distribuido por una persona identificable. 
- Colectivos: el bulo ha sido creado, producido o distribuido por un colectivo social.

Elementos del desorden informativo según el mensaje: ¿qué tipo de mensaje era?, ¿qué formato tomó?, ¿cuáles fueron las características?

\section{Tema sobre el que versa el desorden informativo}

- Violencia de género: el contenido afecta a mujeres víctimas de algún tipo de ataque, lesión o agresión sexual, física, verbal, psicológica, intelectual, etc. por su condición de mujer.

- Feminismos: la información afecta al movimiento social para desprestigiarlo o para difamar a quienes lo ejercen, defienden e integran.

- Personajes de la actualidad: el/la protagonista de la información es un personaje reconocido de la sociedad.

- Mujeres en la historia: el bulo versa sobre una mujer célebre en la historia, normalmente, con la intención de dañar su imagen, difamarla o cuestionar su papel.

- Derechos y legislación: el contenido trata sobre derechos, normativas o leyes que afectan a las mujeres por su condición.

\section{Formato en el que se presenta el desorden informativo}

- Texto: el bulo creado responde a un texto escrito. Puede ser una frase sacada de contexto, un texto completo, un tuit, un comentario en Facebook, etc.

- Vídeo: el bulo creado se presenta en formato audiovisual. Puede ser un montaje de imágenes falsas o con datos e información falsa sobreimpresa, con una voz en off o protagonizado por un busto parlante. También puede darse en forma de deepfake (un vídeo falso en el que se modifica el rostro del protagonista con algoritmos e inteligencia artificial).

- Imágenes: el bulo creado puede responder a una fotografía manipulada, un montaje, un meme o una imagen descontextualizada. 


\section{Propósito del desorden informativo}

- Político: el bulo tiene un propósito propagandístico o ideológico. Pretende movilizar a la opinión pública o desestabilizar un sistema.

- Cultural: el bulo busca causar daño o difamar a una persona o grupo por su clase social, modo de vida, costumbres, etnia, conocimientos, etc.

- Religioso: el bulo tiene como tema central la religión, normalmente, para hacer daño o difamar a un colectivo por sus creencias.

- Humorístico: el bulo tiene una intención lúdica y busca entretener al público.

- Personal: el bulo tiene como fin dañar la imagen pública de una persona u obtener un beneficio particular del engaño.

- Económico: el bulo tiene una intención comercial o fines lucrativos con efectos sobre el consumidor/usuario.

- Publicitario: el bulo no solo tiene una intención comercial o fines lucrativos, sino que también puede buscar difamar o causar un daño relacionado con la reputación de una marca, empresa o negocio.

\section{Elementos del desorden informativo según el intérprete}

- Por iniciativa del medio: el medio encuentra un contenido falso y lo desmiente.

- Colaboración del usuario: el medio se hace eco de una denuncia de un usuario/a sobre un bulo y lo desmiente.

\section{Resultados}

Los principales resultados que se han obtenido, en este estudio, son representativos del universo de estudio de los $\mathrm{N}=71$ bulos analizados en Maldito Feminismo; en ningún caso, estos resultados deben interpretarse como valores extrapolables a otras noticas falsas. Por tanto, siendo conscientes de la validez interna de este estudio, se ha detectado un número significativo de bulos de contenido engañoso 
$(35,2 \%)$ relacionados con el feminismo, como el que afirma que la exministra de Sanidad, Carmen Montón (PSOE), dijese que "la familia es la derrota de las mujeres"1. Tal y como se muestra en el Gráfico 1, también se ha localizado, aunque en menor medida, contenido manipulado $3(22,5 \%)$-que afirma que el puente que se derrumbó en Florida estaba construido solo por mujeres-; contexto falso ${ }^{4}(18,3 \%)$ -el bulo es un vídeo donde aparece un hombre explicando que las mujeres víctimas mortales de violencia de género representen "menos de un 5\%" en Madrid-; información satírica $(14,1 \%)$-como el que asegura que científicos saudíes han dicho que la mujer es un mamífero, pero no humano- y bulos con conexión falsa ${ }^{5}$ $(9,9 \%)$-como el bulo donde utiliza una foto de los juzgados de violencia sobre la mujer, donde se instaló una red, para afirmar que es para evitar que los detenidos por violencia machista se arrojaran al vacío-. De los casos analizados, no se han identificado noticias con contenido impostor ni contenido fabricado.

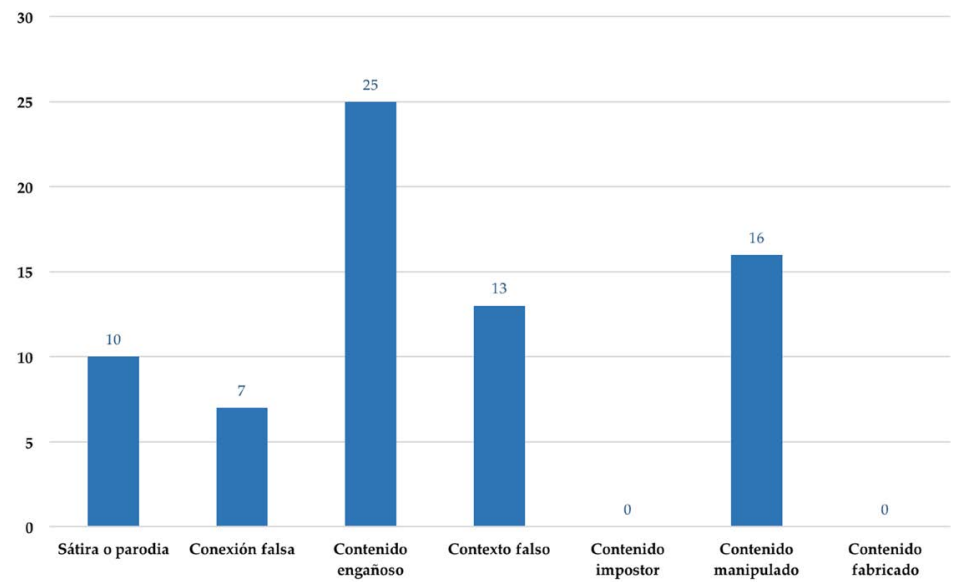

Gráfico 1: Tema sobre el que versa el desorden informativo Fuente: Elaboración propia.

En relación con el agente que creó o distribuyó el bulo, se pudo comprobar que las redes sociales fueron el agente más destacado $6(50,7 \%)$-como el vídeo de Putin, en el que supuestamente hablaba sobre feminismo, que se hizo viral en Facebook-, seguido, por amplio margen, de la prensa ${ }^{7}(26,8 \%)$-como el bulo publicado por el diario Mediterráneo digital, donde advertía de que "feminazis guarrindongas" iban a simular un aborto en una iglesia de Valladolid-, emisores anónimos ${ }^{8}(11,3 \%)$ 
-como el de unas supuestas declaraciones de Marie Curie, en las que afirmaba: "nunca he creído que por ser mujer deba tener tratos especiales"-, particulares $(8,4 \%)^{9}$-como las declaraciones del presidente de la Asociación Profesional de Criminólogos de España, Carlos Cuadrado, donde afirmaba, sin fundamento, que 67 menores habían sido asesinados por su madres. Esta cifra fue posteriormente recogida y difundida por Fernando Sánchez Dragó, en su columna en el diario El Mundo- y colectivos ${ }^{10}(2,8 \%)$-como el bulo sobre un seminario sobre terraplanismo, desde la perspectiva feminista, organizado por una supuesta escuela de estudios de género de la Universidad Nacional de Costa Rica-. En cambio, tal y como se puede ver en el Gráfico 2, no se detectaron bulos creados o distribuidos por la televisión o la radio.

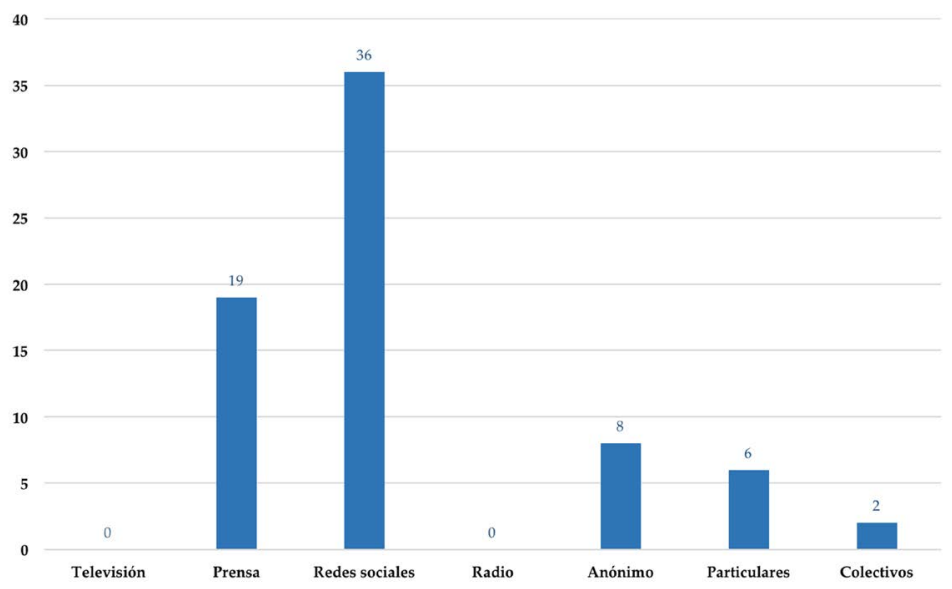

Gráfico 2: Elementos del desorden informativo según el agente Fuente: Elaboración propia.

En el Gráfico 3, se puede apreciar que el tema feminismos ${ }^{11}(56,4 \%)$ es el más representativo de los bulos, aunque también se han registrado mensajes sobre violencia de género ${ }^{12}(24 \%)$; sobre personajes reconocidos de la sociedad ${ }^{13}(8,4 \%)$; sobre derechos, normas o leyes que afectan a las mujeres ${ }^{14}(8,4 \%)$; y noticias que buscan difamar o dañar la figura de mujeres célebres en la historia ${ }^{15}(2,8 \%)$. 
Desinformación de género: análisis de los bulos de Maldito Feminismo | 206 MONOGRÁFICO

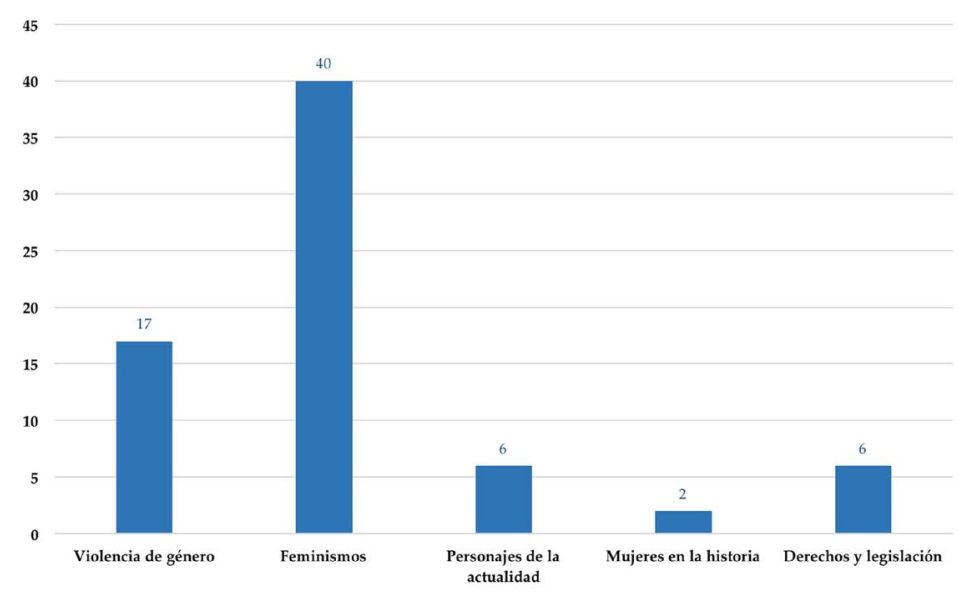

Gráfico 3: Elementos del desorden informativo según el mensaje: tema sobre el que versa la noticia falsa

Fuente: Elaboración propia.

El texto ${ }^{16}(62 \%)$ es el formato más común de los bulos ubicados en Maldito Feminismo. También se han identificado imágenes ${ }^{17}(26,7 \%)$ y vídeo ${ }^{18}(11,3 \%)$, pero, como se puede observar en el Gráfico 4, son formatos menos habituales en los bulos relacionados con el feminismo.

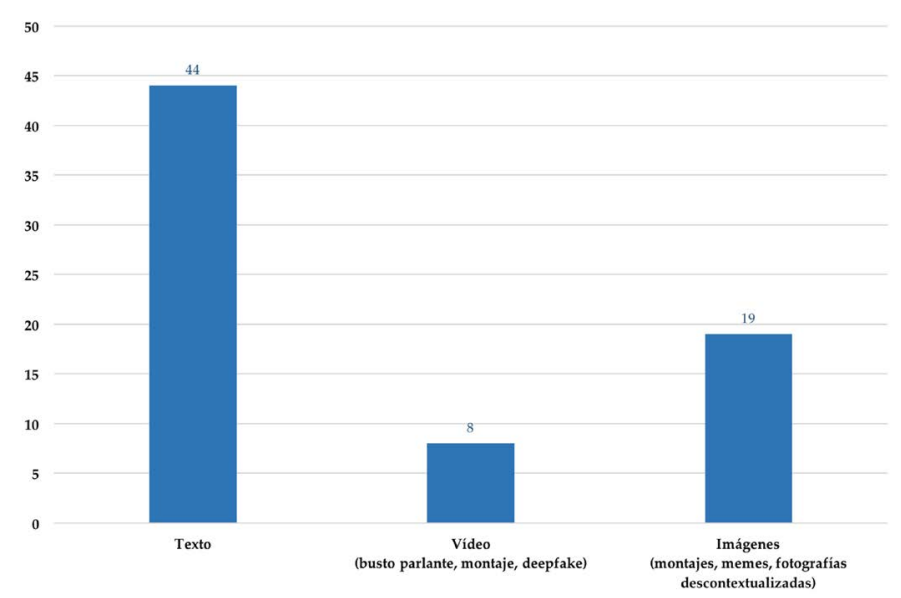

Gráfico 4: Elementos del desorden informativo según el mensaje: formato en el que se presenta la noticia falsa

Fuente: Elaboración propia. 
El Gráfico 5 muestra que, en el 52,1\% de los casos analizados, el bulo tiene un propósito político o ideológico ${ }^{19}$, como el que afirma que las feministas van a obligar a las mujeres a dejar de depilarse. También es significativo que el 25,4\% de noticias falsas tienen una finalidad cultural ${ }^{20}$, es decir, que quieren causar daño 0 difamar a una persona o grupo por su clase social, modo de vida, costumbres, etnia, conocimientos, etc -como el bulo que dice que una mujer ha puesto de nombre a su hijo 'Vagina' para luchar contra los estereotipos de género-. Aunque con una menor presencia, los bulos relacionados con el feminismo también tienen objetivo humorístico ${ }^{21}(11,3 \%)$-como el que se difundió desde una cuenta de perfil falsa, de una supuesta feminista, que decía que "los tampax son un producto diseñado por hombres opresores"-, religioso ${ }^{22}(5,6 \%)$-como el que afirma que un sacerdote se ofrece a realizar exorcismos a feministas-, personal $^{23}(4,2 \%)$-como el bulo sobre el discurso de Vladimir Putin donde, supuestamente, habla de ideología de género- y económico $^{24}(1,4 \%)$-como el que afirma que el Gobierno ha destinado 630 millones de euros para ayudar al desarrollo de asociaciones feministas y LGTBI-. Sin embargo, no se han encontrado noticias falsas con un propósito publicitario.

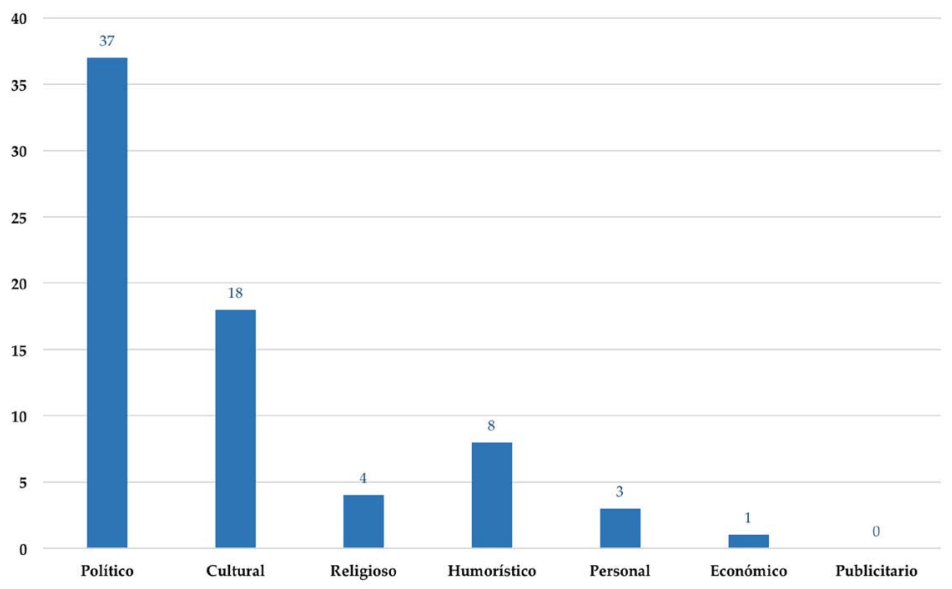

Gráfico 5: Elementos del desorden informativo según el mensaje: propósito de la noticia falsa Fuente: Elaboración propia. 
Finalmente, cabe resaltar que, en el $67,6 \%$ de las ocasiones, Maldito Feminismo encuentra el contenido falso y lo desmiente ${ }^{25}$. Esto significa, como se observa en el Gráfico 6, que los usuarios han desmentido o denunciado el $32,4 \%$ de los bulos que se han publicado en la plataforma ${ }^{26}$.

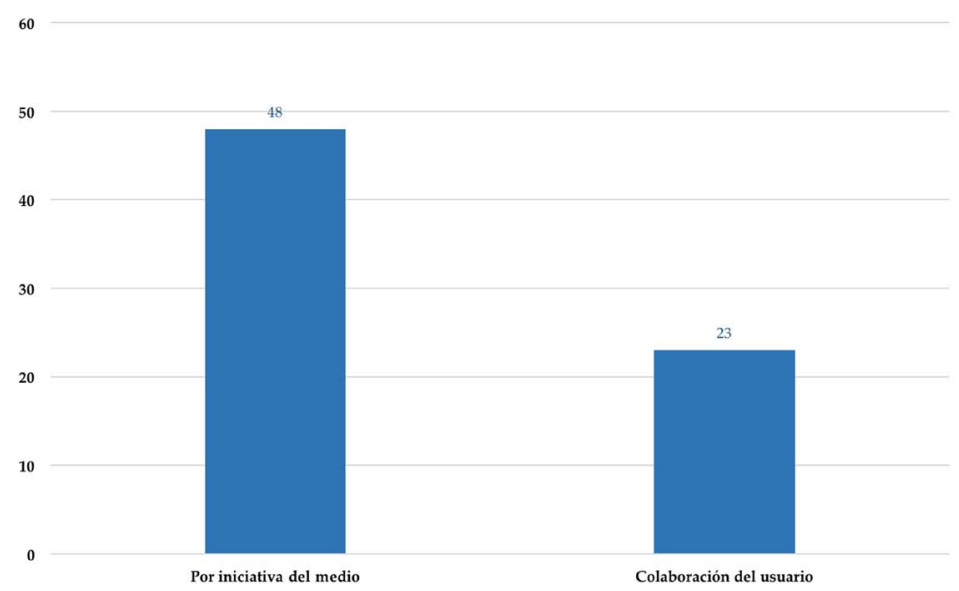

Gráfico 6: Elementos del desorden informativo según el intérprete Fuente: Elaboración propia.

En líneas generales, siendo conscientes de las limitaciones del estudio, se infiere que los bulos detectados por Maldito Feminismo son noticias falsas de contenido engañoso, que buscan dañar el feminismo (ya que este es el tema principal de la mayoría de bulos analizados) y tienen un propósito político. Estos desórdenes informativos se crean y distribuyen, principalmente, a través de las redes sociales en formato texto. Además, los usuarios colaboran y participan en la detección y denuncia de los bulos, aunque, normalmente, suele ser la plataforma Maldita Feminismo quien identifica, localiza y delata la mayoría de noticias falsas.

\section{Discusión}

Los resultados de este trabajo nos permiten afirmar que el desorden informativo que afecta a las mujeres presenta unas características comunes y tiene, principalmente, una intención incriminatoria, respondiendo así a la primera pregunta de investigación (PI1) y de acuerdo con la definición científica de este tipo de conte- 
MONOGRÁFICO

nidos (Derakhshan \& Wardle, 2017). También amplía y explica, en mayor profundidad, los resultados en España apuntados por el CAC (2018).

Además, es un desorden creado, producido o distribuido, la mayor parte de las veces, desde las redes sociales $\mathrm{y}$, en segunda instancia, en medios digitales, lo que resuelve la segunda pregunta de investigación (PI2). No es extraño que la gran mayoría de los bulos que han pasado por la revisión de Maldita.es se hayan difundido en plataformas sociales. Es en el entorno digital donde la desinformación encuentra su acomodo natural, dada la sencillez en su difusión, la falta en muchas ocasiones de un agente intermedio que controle su veracidad o la facilidad con la que en redes desaparece o se diluye la fuente original. Además, en Twitter, Instagram o WhatsApp, por citar algunas plataformas, no es fácil profundizar en las informaciones e, incluso, el lenguaje se desvirtúa, por ello son canales ideales para la difusión de bulos. Estos datos nos recuerdan la advertencia de Johnson, Bichard \& Zhang (2009) acerca del impacto que pueda tener entre la opinión pública compartir estos contenidos y que, a largo plazo, puede construir "guetos digitales" 0 "ciberguetos" (p.60).

En el caso de aquellos bulos que se difunden a través de la prensa digital, lo más frecuente es que se haga a través de medios nativos digitales con poca trayectoria, de carácter sensacionalista (a veces reconocido por ellos mismos), que buscan que ese contenido originalmente publicado en una web acabe, precisamente, en las redes sociales, donde encontrarán más eco. Es un tipo de prensa muy concreto que se basa en el rumor. Por otro lado, también confirma la definición de la Comisión Europea (2018) y la de los autores (Derakhshan \& Wardle (2017), Tandoc y Lim \& Ling (2018) \& Molina, Sundar, Le \& Lee (2019), que dice que las noticias falsas se apropian de la apariencia de las noticias reales.

Centrándonos en las características de los bulos sobre las mujeres publicados en Internet (PI3), podemos decir que estos se distinguen también por tratar sobre feminismo. Es precisamente el movimiento feminista el objeto de parodia, de desinformación o de manipulación. Se hacen afirmaciones exageradas y sorprendentes sobre la relación entre hombres y mujeres que se atribuyen de forma falsa a colectivos feministas o a mujeres que los representan, lo que coindice con las 
afirmaciones de Steinem (2016) y 0cceñola (2018). De igual forma, es frecuente el contenido inventado o manipulado para socavar la credibilidad y dignidad del feminismo.

La violencia de género aparece con asiduidad en los bulos, bien para cuestionar su importancia o para manipular las cifras de mujeres agredidas o de denuncias falsas de violencia de género. Otros temas hacen referencia a personajes de actualidad reconocibles por la audiencia o a medidas de índole legislativa. Estos desmentidos concuerdan con el tipo de agresiones denunciadas a través de los testimonios de la periodista Jamela Alindogan y de la vicepresidenta del Gobierno de Filipinas, Leonor Robredo (Occeñola, 2018).

Otro rasgo característico es que la mayor cantidad de bulos analizados, en este trabajo, son textos. Es comprensible, ya que en no pocas ocasiones son frases fáciles, comentarios inmediatos en los que se cita a personas o colectivos. Aunque a priori puede parecer que la imagen tiene una fuerza comunicativa mayor, es con el lenguaje escrito con lo que se está haciendo más daño. La sencillez de la difusión del texto predomina sobre la manipulación de las imágenes, que exige de mayor pericia y más tiempo.

Finalmente, el propósito de los bulos sobre mujeres, detectados por Maldita.es, es mayoritariamente político, entendido en sentido propagandístico o ideológico: pretende movilizar a la opinión pública o desprestigiar al feminismo. Estas mentiras, como revela el Eurobarómetro (2018), ponen en riesgo los procesos y valores políticos democráticos. Es esta la categoría de análisis más compleja, ya que podríamos entender que, al final, en lo que se refiere a las mujeres y a su bienestar, en sentido amplio, todo es político. Hemos considerado, sin embargo, otras categorías que aportan riqueza al análisis. Así, se han registrado bulos referidos a la identidad, la vida o las costumbres de las mujeres que se han categorizado como «culturales», que son los más frecuentes tras los políticos.

Por último, más de la mitad de los bulos han sido verificados por Maldito Feminismo, frente a la otra mitad, que han sido denunciados y detectados por la comunidad de usuarios. Este resultado refuerza la idea de que, en la actualidad, el activismo de verificación está emergiendo tímidamente en el panorama mediático 
y social. A diferencia del periodismo de verificación, que entiende el proceso de fact-checking como una labor más dentro de su rutina profesional periodística, el activismo de verificación es un formato en sí mismo: es un arquetipo de reivindicación (no un modelo de negocio) que no se centra solo en identificar y señalar bulos, sino que contextualiza, investiga y denuncia las noticas falsas, con el fin de alfabetizar a la sociedad, de concienciar a los individuos sobre los peligros de la desinformación y de fomentar una actitud crítica y reflexiva.

En definitiva, el activismo de verificación busca el bienestar social y denuncia las injusticias, al igual que cualquier otra forma de protesta. En este sentido, el activismo de verificación hibrida algunas cualidades del periodismo de verificación y del activismo mediático, pero cada vez es más evidente que se va perfilando como un movimiento autónomo en auge. Así mismo, en el caso que nos concierne, el activismo de verificación se manifiesta como una práctica más, aunque todavía en ciernes, de la actual cuarta ola del feminismo o ciberfeminismo (Fernández, Corredor \& Santín, 2011; García Aguilar, 2015; Núñez Puente, 2016; Moghaddam, 2019; McAdam, 2020), ya que supone una forma de empoderamiento de la mujer en el escenario online.

Con todo, Maldito Feminismo es una sección muy incipiente todavía y, por ello, las unidades de análisis de esta investigación se han visto limitadas a $\mathrm{N}=71$ bulos. A pesar de este carácter emergente, es importante seguir estudiando la evolución de las noticias falsas en la plataforma, con el fin de descubrir cambios de comportamientos y actitudes de los agentes y del intérprete, así como las posibles transformaciones del mensaje (formato, tema y propósito).

\section{Referencias}

Ajder, H., Patrini, G., Cavalli, F. \& Cullen, L. (2019). The state of deepfakes landscape, threats, and impact. Ámsterdam: Deeptrace. Recuperado de https:// bit.ly/35FD9jA

Bardin, L. (1991). Análisis de contenido (Vol. 89). Madrid: Ediciones Akal.

Barranquero, A. \& Meda, M. (2015). Los medios comunitarios y alternativos en el ciclo de protestas ciudadanas desde el 15M. Athenea Digital, 15(1), 139-170. doi: https://doi.org/10.5565/rev/athenea.1385 
Bedau, H. A. (1961). On civil disobedience. The Journal of Philosophy, 58(21), 653665. doi: $10.2307 / 2023542$

Brandtzaeg, P. B., Lüders, M., Spangenberg, J., Rath-Wiggins, L. \& Følstad, A. (2016). Emerging journalistic verification practices concerning social media. Journalism Practice, 10(3), 323-342. doi: 10.1080/17512786.2015.1020331

Carreón, R. C. \& Garza, V. S. (2016) Percepción del feminismo entre hombres y mujeres. Revista Status, 1(1), 76-99

Comisión Europea (2018). A multi-dimensional approach to disinformation. Report of the independent High level Group on fake news and online disinformation. Recuperado de https://bit.ly/37TYo2T

Conroy, N. J., Rubin, V. L. \& Chen, Y. (2015). Automatic deception detection: Methods for finding fake news. Proceedings of the Association for Information Science and Technology, 52(1), 1-4. doi: 10.1002/pra2.2015.145052010082

Consejo del Audiovisual de Cataluña (2018). Las fake news en Internet. El discurso de género. Recuperado de https://bit.ly/33F4Jfy

Coromina, 0. \& Padilla, A. (2018). Análisis de las desinformaciones del referéndum del 1 de octubre detectadas por Maldito Bulo. Quaderns del CAC, 21(44), 17-26.

De Miguel, A. A. (2008). Feminismo y juventud en las sociedades formalmente igualitarias. Revista de Estudios de Juventud, (83), 29-45.

Derakhshan, H. \& Wardle, C. (2017). Information Disorder: Definitions. AA. VV., Understanding and Addressing the Disinformation Ecosystem, 5-12. University of Pennsylvania: Annenberg School for Communication.

Domínguez, H. (2015). Activismo mediático en los albores de Internet: el caso del movimiento Okupa de Barcelona. COMMONS. Revista de Comunicación y Ciudadanía Digital, 4(2), 93-123.

Echevarría, B. (2016). Más fact-checking contra la «posverdad». Cuadernos de periodistas, 33, 9-16.

Eurobarómetro (2018). Flash Eurobarometer 464: Fake News and Disinformation Online Bruxelles: Eurobarometer. Recuperado de https://bit.ly/35PUTbQ

Fabry, M. (2017, 24 de agosto). Here's How the First Fact-Checkers Were Able to Do Their Jobs Before the Internet. Time. Recuperado de https://bit.ly/35FEdnA

Fernández, D., Corredor, P. \& Santín, M. (2011). Nuevos espacios de comunicación, relación y activismo en la era digital: la Red como oportunidad para el feminismo. Asparkía, 22, pp. 61-72. 
Fox, D. (1981). El proceso de investigación en educación. Pamplona: Eunsa.

García Aguilar, M. D. C. (2015). Feminismo contemporáneo: más allá de la posmodernidad. PALOBRA," palabra que obra", 14(14), pp. 158-172.

Gill, R. (2007). Postfeminist media culture: Elements of a sensibility. European Journal of Cultural Studies, 10(2), pp. 147-166. doi: 10.1177/1367549407075898 Global Disinformation Index (2019). The Quarter Billion Dollar Question: How is Disinformation Gaming Ad Tech? Recuperado de https://bit.ly/380DnUu

Graves, L. (2013). Deciding what's true: Fact-checking journalism and the new ecology of news (Doctoral dissertation). Nueva York: Columbia University.

Graves, L., Nyhan, B. \& Reifler, J. (2016). Understanding innovations in journalistic practice: A field experiment examining motivations for fact-checking. Journal of Communication, 66(1), 102-138. doi: 10.1111/jcom.12198

Graves, L. (2017). Anatomy of a fact check: Objective practice and the contested epistemology of fact checking. Communication, Culture \& Critique, 10(3), 518537. doi: $10.1111 /$ cccr.12163

Habermas, J. (2002). Ensayos políticos. Barcelona: Ediciones península.

Hammer, R. y Kellner, D. (2009). Third wave feminism. Sexualities and the adventures of the posts. En E. A. Roustang-Stoller (ed.), Women in the public sphere (pp. 219-234). Nueva York: Palgrave Macmillian.

Hermida, A. (2015). Nothing but the truth: Redrafting the journalistic boundary of verification. En M. Carlson \& S. C. Lewis (eds.), Boundaries of journalism. Professionalism, Practices and Participation (pp. 37-50). Nueva York: Routledge. Johnson, T., Bichard, S. \& Zhang, W. (2009). Communication Communities or "CyberGhettos?": A Path Analysis Model Examining Factors that Explain Selective Exposure to Blogs. Journal of Computer-Mediated Communication, 15(1), pp. 60-82. doi: 10.1111/j.1083-6101.2009.01492.x

Krippendorff, K. (2018). Content analysis: An introduction to its methodology. California: Sage publications.

Lazar, M. M. (2009). Communicating (post)feminisms in discourse. Revista Discourse \& Communication, 3(4), 339-344. doi: 10.1177/1750481309343856

Lewis, R. \& Marwick, A. (2017). Taking the Red Pill: Ideological Motivations for Spreading Online. Understanding the Structure and Dynamics of Disinformation in the Online Information Ecosystem, 18-22. University of Pennsylvania: Annenberg School for Communication. doi: 10.1080/15401383.2016.1249815 
Desinformación de género: análisis de los bulos de Maldito Feminismo | 214 MONOGRÁFICO

Magallón, R. (2018). La biblioteca digital sobre Donald Trump. Fact-checking frente a fake news. Estudios sobre el Mensaje Periodístico, 24(1), 273-282. doi: 10.5209/ESMP.59949

Magaloni, B. (1990). La desobediencia civil en la democracia constitucional. Estudios, (22), 17-46.

Marcone, J. (2009). Las razones de la desobediencia civil en las sociedades democráticas. Andamio, 5(10), 39-69.

Mastretta, A. (2004). El cielo de los leones. Barcelona: Seix Barral Biblioteca Breve McAdams, M. (2020). Digital girl: cyberfeminism and the emancipatory potential of digital entrepreneurship in emerging economies. Small Business Economy, pp. 1-14. doi: https://doi.org/10.1007/s11187-019-00301-2

McRobbie, A. (2007). The aftermath of feminism: Gender, culture and social change. California: Sage Publications.

Moghaddam, R. (2019). Struggle for Equality: From the constitutional revolution to cyber feminism with a focus on the role of new media in the women's movement in Iran (Ph.D thesis). Berlin: Freie Universität Berlin.

Molina, J. P. \& Magallón, R. (2019). Procedimientos para verificar y desmontarinformaciones falsas basadas en el discurso del odio. El caso de Maldita Migración. RAEIC, Revista de la Asociación Española de Investigación de la Comunicación, 6(12), 95-122.

Molina, M. D., Sundar, S. S., Le, T. \& Lee, D. (2019). "Fake News" Is Not Simply False Information: A Concept Explication and Taxonomy of Online Content. American Behavioral Scientist, 1-33. doi: 10.1177/0002764219878224

Núñez Puente, S. (2016). FEMEN, ciberfeminismo, democracia radical y la política del cuerpo. En V. Martín \& D. Etura (eds.), La comunicación en clave de igualdad de género (pp. 41-56.). Madrid: Fragua.

Nyhan, B. \& Reifler, J. (2015). Estimating fact-checking's effects. Arlington, VA: American Press Institute.

Occeñola, P. (2018). Fake news real women: Disinformation gone macho. When disinformation is weaponized against women, misogyny rears its ugly head. Rappler. Recuperado de https://bit.ly/350kphW

Pal, A. \& Banerjee, S. (2019). Understanding Online Falsehood From the Perspective of Social Problem. En I. E. Chiluwa \& S. A. Samoilenko (eds.), Handbook of Research on Deception, Fake News, and Misinformation Online (pp. 1-17). Hershey (EEUU): IGI Global. 
Pardy, N. (2018, 3 de mayo). How The Fake News Industry Weaponizes Women. Refinery29. Recuperado de https://r29.co/2L7jzF3

Plant, S. (1998). Zeros and Ones: Digital Women + the New Technoculture. London: Fourth Estate.

Press, A. P. (2011). "Feminism? That's so seventies"': Girls and young women discuss femininity and feminism in America's next top model. En R. Gill y C. Scharff (eds.), New femininities, postfeminism, neoliberalism and subjectivity (pp. 117-133). Hampshire: Palgrave Macmillan.

Rawls, J. (1979). Teoría de la justicia. México: Fondo de Cultura Económica.

Rovira, G. (2013). Activismo mediático y criminalización de la protesta: medios y movimientos sociales en México. Convergencia. Revista de Ciencias Sociales, 20(61), 35-60.

Sobieraj, S. (2018). Bitch, slut, skank, cunt: Patterned resistance to women's visibility in digital publics. Information, Communication \& Society, 21(11), 1700-1714. doi: 10.1080/1369118X.2017.1348535

Stabile, B., Grant, A., Purohit, H. \& Harris, K. (2019). Sex, Lies, and Stereotypes: Gendered Implications of Fake News for Women in Politics. Public Integrity, 21(5), 491-502. doi: 10.1080/10999922.2019.1626695

Steinem, G. (2016). Mi vida en la carretera. Salamanca: Alpha Decay.

Stencel, M. \& Luther. J. (2019, 21 de octubre). Reporters' Lab fact-checking tally tops 200. Recuperado de https://bit.ly/2Dun9ET

Tandoc Jr, E. C., Lim, Z. W. \& Ling, R. (2018). Defining 'fake news' A typology of scholarly definitions. Digital Journalism, 6, 137-153. doi: $0.1080 / 21670811.2017 .1360143$

Thoureau, H. D. (2002). Del deber de la desobediencia civil. Palma de Mallorca: Jose J. de Olañeta

Valera, N. (2013). Feminismo para principiantes. Barcelona: Sipan Barcelona Network S. L.

Wichels, S. (2019). "Femenina, sí. feminista, no." Demonización del feminismo en blogs portugueses. En J. C. Suárez Villegas, S. Marín Conejo \& P. Panarese (eds.), Comunicación, género y educación. Representaciones y (de)construcciones (pp. 115.121). Madrid: Dykinson S.L. 


\section{Notas}

[1] Este bulo puede consultarse en el siguiente enlace: https://bit.ly/2HLkjh7

[2] Este bulo puede consultarse en el siguiente enlace: https://bit.ly/38RoX9e

[3] Este bulo puede consultarse en el siguiente enlace: https://bit.ly/39ZUTIE

[4] Este bulo puede consultarse en el siguiente enlace: https://bit.ly/32mm5yC

[5] Este bulo puede consultarse en el siguiente enlace: https://bit.ly/2PjfrUF

[6] Este bulo puede consultarse en el siguiente enlace: https://bit.ly/2wyCHqX

[7] Este bulo puede consultarse en el siguiente enlace: https://bit.ly/2vUqjRT

[8] Este bulo puede consultarse en el siguiente enlace: https://bit.ly/2HPmeRI

[9] Este bulo puede consultarse en el siguiente enlace: https://bit.ly/2ST5uif

[10] Este bulo puede consultarse en el siguiente enlace: https://bit.ly/2vWD6mQ

[11] Como, por ejemplo, el siguiente bulo: https://bit.ly/37SDqQT

[12] Como, por ejemplo, el siguiente bulo: https://bit.ly/2vYyrki

[13] Como, por ejemplo, el siguiente bulo: https://bit.ly/39ZyTxA

[14] Como, por ejemplo, el siguiente bulo: https://bit.ly/2HOYXiP

[15] Como, por ejemplo, el siguiente bulo: https://bit.ly/2PjT29t

[16] Como, por ejemplo, en este bulo: https://bit.ly/39Z5uU0

[17] Como, por ejemplo, en este bulo: https://bit.ly/39XzeRd

[18] Como, por ejemplo, en este bulo: https://bit.ly/2TdyGQm

[19] Este bulo puede consultarse en el siguiente enlace: https://bit.ly/32jAgVf

[20] Este bulo puede consultarse en el siguiente enlace: https://bit.ly/2ST1FtW

[21] Este bulo puede consultarse en el siguiente enlace: https://bit.ly/32jW3fr

[22] Este bulo puede consultarse en el siguiente enlace: https://bit.ly/2Vk6fD5

[23] Este bulo puede consultarse en el siguiente enlace: https://bit.ly/2PinTU0

[24] Este bulo puede consultarse en el siguiente enlace: https://bit.ly/38Vh5U1

[25] Como, por ejemplo, en este bulo: https://bit.ly/37UHfF0

[26] Como, por ejemplo, en este bulo: https://bit.ly/3c29LYU

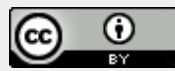

Este obra está bajo una licencia de Creative Commons Reconocimiento 4.0 Internacional. 